\title{
A Diagnostic Tool on Time Perception of Children with ADHD
}

\author{
Pongpanote Gongsook ${ }^{1(\bowtie)}$, Janneke Peijnenborgh ${ }^{2}$, \\ Christian Sallustro ${ }^{1}$, Erik van der Spek ${ }^{1}$, Jun $\mathrm{Hu}^{1}$, Francesco Bellotti ${ }^{3}$, \\ Matthias Rauterberg ${ }^{1}$, and Jos Hendriksen ${ }^{2}$ \\ 1 Department of Industrial Design, Eindhoven University of Technology, \\ 5600 MB Eindhoven, The Netherlands \\ \{p.gongsook, c. sallustro, e.d.v.d.spek, j.hu, \\ G.W.M. Rauterberg\}@tue.nl \\ 2 Kempenhaeghe, Center for Neurological Learning Disabilities, \\ 5591 VE Heeze, The Netherlands \\ $\{$ PeijnenborghJ, HendriksenJ\}@kempenhaeghe.nl \\ 3 ELIOS Lab - DITEN, University of Genova, Via Opera Pia 11/a, \\ 16145 Genoa, Italy \\ franz@elios. unige.it
}

\begin{abstract}
ADHD is among the most common childhood developmental disorder which may affect the school achievements. Children with ADHD may show symptoms of time perception problems. Although ADHD is a clinical diagnosis with several approaches, no diagnostic tool has been designed to detect the symptoms of time perception problems in ADHD children. A computer game can be a powerful tool to be used as part of the psychological assessment and yield better accuracy in ADHD diagnosis. In this paper, we present our concept of a diagnostic tool on time perception for children with ADHD-symptoms.
\end{abstract}

Keywords: ADHD $\cdot$ Diagnostic tool $\cdot$ Serious game $\cdot$ Time perception

\section{Introduction}

Attention Deficit Hyperactivity Disorder (ADHD) has been widely researched in the past decades. Several hypotheses have been formulated on the causes of this disorder, as it could be derived both genetically and environmentally [1]. Some researchers have already proposed a tool targeting the cognitive functions for ADHD diagnosis [2-4].

Children with ADHD may have difficulties in processing, reading and telling time $[5,6]$ and a diminished functioning of reaction time and information processing speed [7]. Therefore, for an alternative to general cognitive measurements, we are interested to investigate the question on whether a computer game on time perception may contribute to a diagnostic process for children aged 4-8 years old. In this paper, we briefly describe what ADHD is and approaches to the diagnosis (Sect. 2), as well as why the diagnosis on time perception using computer games is of importance for our current design and development (Sect. 3). 


\section{Attention Deficit Hyperactivity Disorder (ADHD)}

ADHD is a behavioral and developmental disorder identified by the Diagnostic and Statistical Manual of Mental Disorders, Fourth Edition (DSM-IV) [8]. Its symptoms must be present before the age of seven, persist for at least six months, must be maladaptive for the development of the child, inconsistent with the person's developmental level, and severe enough to impact daily functioning across several environment settings [9]. They reveal subtle but clear impairments in several complex functional systems such as selective attention, memory, motor speed and visuomotor ability, inhibitory control, and working memory [2].

Despite that we have DSM-IV guidelines for ADHD, no absolute methods for diagnosis have been defined. Moreover, it is difficult to diagnose ADHD since this developmental disability can not be diagnosed until children are six years of age, when they are exposed to classroom learning of academic tasks [10]. There are some computer games designed for ADHD diagnosis for example IntegNeuro [11], and Groundskeeper [12]. IntegNeuro is designed to assess people aged 6-96 years old, while Groundskeeper has been designed to target people from 6-17 years old.

We agree with Greenberg [13] that there is no such game that fits all age groups, the diagnostic game should be tailored to match the specific age group. The target age group of children in our project is 4-8 years old, the reason for choosing this age range complies with what Kalff [14] stated: (1) there is a limited amount of research conducted with children 4-8 years old, and (2) The symptoms that can be diagnosed as belonging to ADHD are not obviously shown but will gradually emerge when the children grows up.

\section{A Diagnostic Tool on Time Perception}

Time perception is a conceptual understanding that enables us to predict, anticipate, and respond to events occurring in the environment [15]. Children with ADHD may have deficits in working memory, that is related to time perception [16]. In addition, we know that children with ADHD may have brain abnormalities in some regions such as the pre-frontal cortex, basal ganglia, striatum, corpus callosum, nucleus caudatus, globus pallidus and cerebellum [17]. Those regions relate to the conceptual understanding of time [18]. Moreover, unlike other symptoms that could decline when the child grow up, time perception problems still remain even when the child becomes an adult [19]. This makes time perception a suitable factor for diagnosis. Therefore, we contend that if we have a better understanding of time perception in children with $\mathrm{ADHD}$, we can train time perception, which contributes to the treatment of attention problems in children with ADHD.

\subsection{Game as a Diagnostic Tool}

Computer games offer players with intense and often relentless action, immediate rewards, challenging, and appealing stories, which seems to be something the brain of 
children with ADHD eagerly desire, and they hardly get from the everyday life outside the digital world [20]. The game we are creating is well fitted to the term of serious game [21]. It is designed specifically for diagnostic purposes with immersive environments, and multimodal interaction.

We aim at giving them the feeling that they are playing instead of being tested. Computer games could give an advantage over a plain psychological test because it does not induce a type of the Hawthorne effect [22], where kids behave differently when they know they are being studied. Using a game could therefore improve the ecological and external validity of ADHD diagnosis.

\subsection{Current Project Approach}

We have formed a collaborative and multidisplinary working team of computer scientists and designers from Eindhoven University of Technology, and psychologists from Kempenhaeghe, center for neurological learning disabilities. The development of the diagnostic tool is roughly divided into three phases in each iteration: design, implementation, and evaluation, with a spiral model $[23,24]$. In the design phase we applied participatory design model (PD) [25] and user-centred design (UCD) [26]. We working with psychologists for their requirement, and re-design the diagnostic tool regarding to their feedback and comments. Children have been involved and observed do they understand our designed user-interaction, and asked how the non-player control characters in the game should looks like (see Fig. 1).
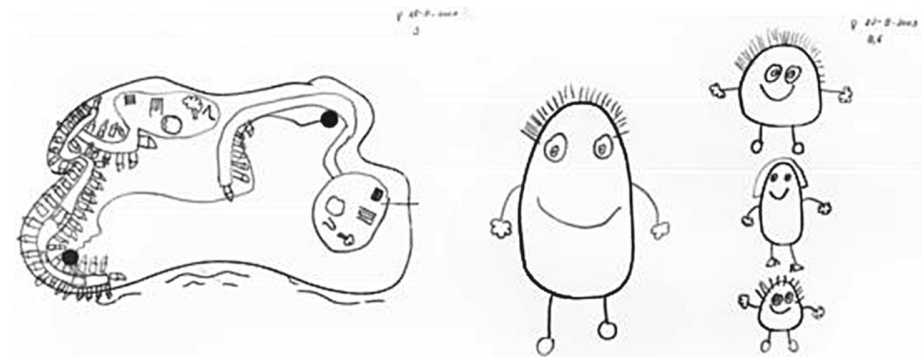

Fig. 1. Sample design of game scene and non-player control characters by a child

According to Zapata-Rivera and Bauer [27], there are some important items that should be taken into account when designing the game: (1) avoid to construct irrelevant content which need knowledge or skills on the player's side that are unrelated to our assessment goal, (2) limit other types of user interaction, but do not make the game boring or repetitive, (3) if we need more cognitive processing in working memory, we must introduce high interactivity and engagement, (4) players need support from ingame tutorial to become familiar and know how to interact with the game environment, and (5) provide formative feedback to the players. 


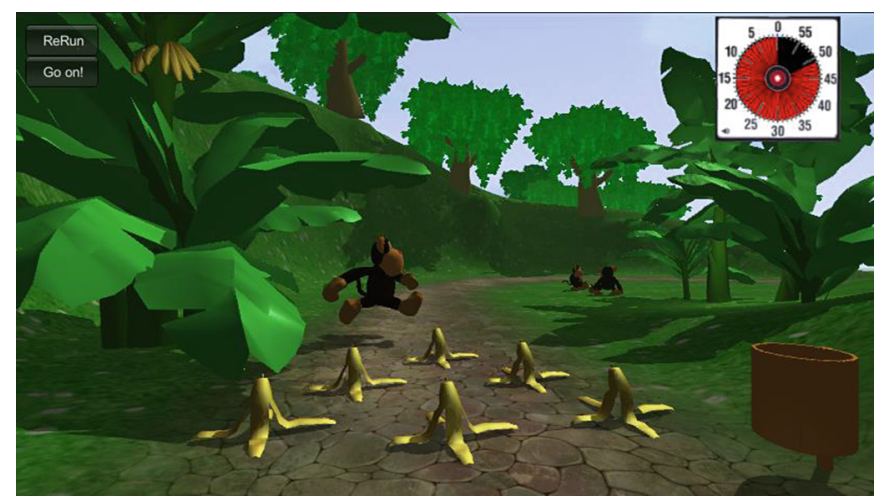

Fig. 2. Sample screenshot of the diagnostic tool

The diagnostic tool will be used with a supervision from a psychologist. It is a single player game display in first person view using 23 inch LCD touch screen. Duration for diagnosing with our tool is set to the maximum of 30 minutes per session so the child will not feel too much fatigue. The diagnostic tool has a controlled linear story to secure that every child who plays our diagnostic tool will experience the same story progression. We have designed mini games to test specific aspects of time perception and related aspects such as time estimation, reaction time, and waiting time behavior.

Figure 2 shows one of the mini games which testing on children inhibition with gonogo signals, the child has to clean banana peels from the pathway but the cleaning will be successful only when the monkey is hiding behind the leftmost banana trees. We believe that children who perform worse in the mini games have more possible deficits in the relevant executive functions. We already had a small evaluation test with normal children and received very positive feedback.

\section{Future Work}

We would like to explore whether information of time perception does contribute to an understanding of children with ADHD. Before going to conduct a clinical experiment with children, we will conduct a pilot test to get qualitative data and observations from children's behaviors to assess key game features such as usability, usefulness playfulness and attractiveness.

\section{Conclusion}

ADHD is a developmental behavior disorder which impedes the learning achievements of children. Psychologists use a combination of various approaches to diagnose ADHD. But there is no existing computer game which is designed extensively to diagnose possible deficits in time perception which we know is associated with ADHD. 
In this paper we present our concept of a diagnostic tool, and mini games. We strongly believe that a computer game on time perception will definitely contribute to the diagnostic process for children aged 4-8 years old. We are not yet receiving the confirmation, but from the evaluation feedback we consider that we are getting closer to receive the answer soon.

Acknowledgement. This work was supported by the Erasmus Mundus Joint Doctorate in Interactive and Cognitive Environments (ICE), which is funded by the EACEA Agency of the European Commission under EMJD ICE FPA n 2010-0012. We are also very grateful for the collaboration with Dr. Jos Hendriksen, Prof. Dr. Hans Vles, Prof. Dr. Bert Aldenkamp, and Janneke Peijnenborgh MSc. from Kempenhaeghe, Center for Neurological Learning Disabilities, and Christian Sallustro from the User System Interation (USI) program, Eindhoven University of Technology.

\section{References}

1. Attention-Deficit/Hyperactivity Disorder: Causes of ADHD. http://www.webmd.com/addadhd/guide/adhd-causes

2. Gualtieri, C., Johnson, L.: ADHD: Is objective diagnosis possible? Psychiatry (Edgmont). 2, 44-53 (2005)

3. Elwood, R.W.: MicroCog: assessment of cognitive functioning. Neuropsychol. Rev. 11, 89-100 (2001)

4. Gualtieri, C.T., Johnson, L.G.: Reliability and validity of a computerized neurocognitive test battery, CNS Vital Signs. Arch. Clin. Neuropsychol. 21, 623-643 (2006)

5. Hurks, P.P., Hendriksen, J.G.: Retrospective and prospective time deficits in childhood ADHD: The effects of task modality, duration, and symptom dimensions. Child Neuropsychol. 17, 34-50 (2010)

6. Barkley, R., Koplowitz, S.: Sense of time in children with ADHD: effects of duration, distraction, and stimulant medication. J. Int. Neuropsychol. Soc. 3, 359-369 (1997)

7. Leth-Steensen, C., Elbaz, Z.K., Douglas, V.I.: Mean response times, variability, and skew in the responding of ADHD children: a response time distributional approach. Acta Psychol. (Amst) 104, 167-190 (2000)

8. American Psychological Association: Diagnostic and Statistical Manual of Mental Disorders, Washington, D.C. (1994)

9. Goldman, L.S., Genel, M., Bezman, R.J., Slanetz, P.J.: Diagnosis and treatment of attentiondeficit/hyperactivity disorder in children and adolescents. JAMA J. Am. Med. Assoc. 279, 1100-1107 (1998)

10. Glascoe, F.P.: Early detection of developmental and behavioral problems. Pediatr. Rev. 21, 272-279, quiz 280 (2000)

11. New breakthrough in diagnosis of ADHD. http://sydney.edu.au/news/84.html?newsstoryid= 4501

12. Montini, L.: CogCubed Is Using Games to Help Diagnose ADHD. http://www.health2con. com/news/2013/04/16/cogcubed-is-using-games-to-diagnose-adhd/

13. Greenberg, B.S., Sherry, J., Lachlan, K., Lucas, K., Holmstrom, A.: Orientations to video games among gender and age groups. Simul. Gaming 41, 238-259 (2010) 
14. Kalff, A.C., Hendriksen, J.G.M., Kroes, M., Vles, J.S.H., Steyaert, J., Feron, F.J.M., van Zeben, T.M.C.B., Jolles, J.: Neurocognitive performance of 5- and 6-year-old children who met criteria for attention deficit/hyperactivity disorder at 18 months follow-up: results from a prospective population study. J. Abnorm. Child Psychol. 30, 589-598 (2002)

15. Toplak, M.E., Rucklidge, J.J., Hetherington, R., John, S.C.F., Tannock, R.: Time perception deficits in attention-deficit/hyperactivity disorder and comorbid reading difficulties in child and adolescent samples. J. Child Psychol. Psychiatry 44, 888-903 (2003)

16. Barkley, R.A., Murphy, K.R., Bush, T.: Time perception and reproduction in young adults with attention deficit hyperactivity disorder. Neuropsychology 15, 351-360 (2001)

17. Wassenberg, R., Hendriksen, J.G., Hurks, P.P., Feron, F.J., Keulers, E.H., Vles, J.S., Jolles, J.: Development of inattention, impulsivity, and processing speed as measured by the $\mathrm{d} 2$ Test: results of a large cross-sectional study in children aged 7-13. Child Neuropsychol. 14, 195-210 (2008)

18. Toplak, M.E., Dockstader, C., Tannock, R.: Temporal information processing in ADHD: Findings to date and new methods. J. Neurosci. Methods 151, 15-29 (2006)

19. Biederman, J., Mick, E., Faraone, S.V.: Age-dependent decline of symptoms of attention deficit hyperactivity disorder: impact of remission definition and symptom type. Am. J. Psychiatry 157, 816-818 (2000)

20. Bioulac, S., Arfi, L., Bouvard, M.P.: Attention deficit/hyperactivity disorder and video games: a comparative study of hyperactive and control children. Eur. Psychiatry 23, 134-141 (2008)

21. Bellotti, F., Berta, R., De Gloria, A.: Designing Effective Serious Games: Opportunities and Challenges for Research. Int. J. Emerg. Technol. Learn. (iJET) 5, 22-35 (2010)

22. McCarney, R., Warner, J., Iliffe, S., van Haselen, R., Griffin, M., Fisher, P.: The Hawthorne Effect: a randomised, controlled trial. BMC Med. Res. Methodol. 7, 30 (2007)

23. Boehm, B.: A spiral model of software development and enhancement. Computer 21, 61-72 (1988)

24. Rauterberg, M., Strohm, O., Kirsch, C.: Benefits of user-oriented software development based on an iterative cyclic process model for simultaneous engineering. Int. J. Ind. Ergon. 16, 391-410 (1995)

25. Read, J., Gregory, P., Macfarlane, S., Mcmanus, B., Gray, P.: An investigation of participatory design with children - informant, balanced and facilitated design. In: Interaction Design and Children, pp. 53-64 (2002)

26. Rauterberg, M.: User centered design: what, why, and when. In: Graefe, E. (ed.) tekom Jahrestagung, pp. 175-178. Gesellschaft fuer technische Kommunikation e.V, Wiesbaden (2003)

27. Zapata-Rivera, D., Bauer, M.: Exploring the role of games in educational assessment. In: Clarke-Midura, J., Mayrath, M., Robinson, D. (eds.) Technology-Based Assessments for Twenty-First-Century Skills: Theoretical and Practical Implications from Modern Research, pp. 147-169. Information Age, Charlotte (2011) 


\section{Alessandro De Gloria (Ed.)}

Games and Learning Alliance

Second International Conference, GALA 2013 Paris, France, October 23-25, 2013 Revised Selected Papers

Springer 


\section{Lecture Notes in Computer Science}

Commenced Publication in 1973

Founding and Former Series Editors:

Gerhard Goos, Juris Hartmanis, and Jan van Leeuwen

\section{Editorial Board}

David Hutchison

Lancaster University, Lancaster, UK

Takeo Kanade

Carnegie Mellon University, Pittsburgh, PA, USA

Josef Kittler

University of Surrey, Guildford, UK

Jon M. Kleinberg

Cornell University, Ithaca, NY, USA

Friedemann Mattern

ETH Zurich, Zürich, Switzerland

John C. Mitchell

Stanford University, Stanford, CA, USA

Moni Naor

Weizmann Institute of Science, Rehovot, Israel

C. Pandu Rangan

Indian Institute of Technology, Madras, India

Bernhard Steffen

TU Dortmund University, Dortmund, Germany

Demetri Terzopoulos

University of California, Los Angeles, CA, USA

Doug Tygar

University of California, Berkeley, CA, USA

Gerhard Weikum

Max Planck Institute for Informatics, Saarbruecken, Germany 
More information about this series at http://www.springer.com/series/7409 
Alessandro De Gloria (Ed.)

\section{Games and \\ Learning Alliance}

Second International Conference, GALA 2013

Paris, France, October 23-25, 2013

Revised Selected Papers

粤 Springer 
Editor

Alessandro De Gloria

University of Genova

Genova

Italy

ISSN 0302-9743

ISBN 978-3-319-12156-7

ISSN 1611-3349 (electronic)

DOI 10.1007/978-3-319-12157-4

ISBN 978-3-319-12157-4 (eBook)

Library of Congress Control Number: 2014953269

LNCS Sublibrary: SL3 - Information Systems and Applications, incl. Internet/Web, and HCI

Springer Cham Heidelberg New York Dordrecht London

(C) Springer International Publishing Switzerland 2014

This work is subject to copyright. All rights are reserved by the Publisher, whether the whole or part of the material is concerned, specifically the rights of translation, reprinting, reuse of illustrations, recitation, broadcasting, reproduction on microfilms or in any other physical way, and transmission or information storage and retrieval, electronic adaptation, computer software, or by similar or dissimilar methodology now known or hereafter developed. Exempted from this legal reservation are brief excerpts in connection with reviews or scholarly analysis or material supplied specifically for the purpose of being entered and executed on a computer system, for exclusive use by the purchaser of the work. Duplication of this publication or parts thereof is permitted only under the provisions of the Copyright Law of the Publisher's location, in its current version, and permission for use must always be obtained from Springer. Permissions for use may be obtained through RightsLink at the Copyright Clearance Center. Violations are liable to prosecution under the respective Copyright Law.

The use of general descriptive names, registered names, trademarks, service marks, etc. in this publication does not imply, even in the absence of a specific statement, that such names are exempt from the relevant protective laws and regulations and therefore free for general use.

While the advice and information in this book are believed to be true and accurate at the date of publication, neither the authors nor the editors nor the publisher can accept any legal responsibility for any errors or omissions that may be made. The publisher makes no warranty, express or implied, with respect to the material contained herein.

Printed on acid-free paper

Springer is part of Springer Science+Business Media (www.springer.com) 


\section{Preface}

The second GALA Conference was held during October 23-25 at the Dassault Systèmes (Paris). The Serious Games Society supported and organized the conference along with the Games and Learning Association, the Network of Excellence on Serious Games funded by the European Union under the Seventh Framework Programme. The conference has been devoted to Serious Games (SGs) and aimed at gathering, building, and nurturing an expert community on SGs which involves academic, industrial developers, teachers, and corporate decision makers, to promote knowledge share, technology transfer, and business development. SGs aim at improving learning processes by providing attractive, motivating, and effective tools. So far, effectiveness of SGs has been shown by recent studies (e.g., [1,2]), but the potential of SGs in education is still far to be fulfilled. Furthermore, there is a growing need for scientific and engineering methods and tools for efficiently building games as means that provide effective learning experiences (e.g., [3-5]). An effective application of SGs for education and training demands appropriate metrics, analytics, tools, and techniques for in-game user assessment. This can be achieved in particular by measuring elements such as learning outcomes and engagement, considering the twofold nature of SGs as compelling games that achieve precise educational goals (e.g., [6, 7]). Recent technological advances have brought what was once expensive, specialized Human-Computer Interaction (HCI) equipment located in research labs, to our family rooms and classes at an affordable cost. Devices such as stereo cameras, eye trackers, tablets and smartphones, pointing devices, motion sensors, sensors related to the central and peripheral nervous systems (e.g., galvanic skin response, heart rate, neuronal activity) [8, 9], amongst others, not only provide innovative interaction methods and techniques, but also present opportunities to develop innovative solutions for continuous user monitoring and assessment (e.g., [10-12]). All in all, design of SGs is a very complex activity, involving different constraints, targets, and disciplines, which is being investigated but is still far from maturity [13-15]. This book reports the studies presented during the conference, addressing the abovementioned call for paper indications. The book is divided into two parts. The first and main part includes three SG research tracks: design, technology, and application. The second part reports the results of the Workshop "Acquiring 21st Century Skills: gaining insight in the design and applicability of a serious game with 4C-ID" and presents short papers describing the posters exhibited during the conference.

The first research track is dedicated to SG design. The first paper describes the gamification process in a safety and energy-efficiency application context, while the second describes a location-based SG for promoting citizens' preparedness to flooding situations. The third article presents two case studies of SGs for supporting music research, while the fourth gives an overview of the conceptual development and technical implementation of an early staged prototype combining a business simulation and an SG. Learning analytics (LA) are discussed in the next two papers, the first paper devoted to a practical experience on using LAs in educational games and the second 
stressing the importance of the game log files for developing LAs. The last paper of the track deals with the relationship between entertainment games and SGs and what SG designers may learn from entertainment game design. The second research track is devoted to the technology applied in SGs. The first paper presents an accessible multiplatform game engine for a new version of the eAdventure educational game authoring platform. The second paper proposes an agent paradigm as a methodological tool to guide the design of SGs in the social field. The next article presents the F1 game, used to demonstrate how learning takes place in the domain of the Formula 1. An additional paper shows the learning path for solving learning difficulties in the use of money and other basic business activities by kids with cognitive disabilities. Two studies deal with significant enabling technologies. The Haptic technology is presented as a provider of a physical control layer that could enhance the immersion of virtual reality. Voice emotion recognition, on the other hand, is presented in the context of improving learning through webcams and microphone. The flow experience and how it can facilitate the game evaluation and design process is discussed in another paper, while the last article in the track presents the perspective of executive functions and discusses how they can help provide a more coherent approach to understanding the cognitive benefits of playing games. The third track of the research part is dedicated to SG applications. The first paper presents a business simulation game with an agentbased deliberative model of consumer behavior, while second paper deals with the evaluation of team collaboration in digital entertainment games. A cultural heritage application is considered in the next paper, presenting the key features, design solutions, and game mechanics of the Fort Ross Virtual Warehouse SG, while a subsequent study presents a Game-Based Learning MOOC for entrepreneurship. A case study presents how to deal with cultural awareness in a game concerning deployment of troops in Afghanistan. Another study provides a handy toolkit for evaluating the effectiveness of a SG for cultural awareness and heritage. The next paper investigates the gambling interactive experience, understanding how games of chance are structured and how they are related to cognitive errors and biases that occur in both frequent and infrequent gamblers. Another article describes a player-specific conflict handling ontology. The last paper in the track presents a compelling case for the use of games as a method for carrying out useful computational work by players in order to define new tools for designing SGs.

The second part of the book starts with the presentation of a workshop exploring how a widely applied instructional design model, 4C-ID, can ease the uptake of SGs by offering teachers a model fitting their background to assess games on the applicability in their learning contexts. The final part of the book collects short papers describing the exhibited posters, addressing a wide range of topics, from user profiling to knowledge convergence measure and from design to description of new SGs in different application fields.

In summary, as the above description may have shown, we are confident that a variety of stakeholders in the field of SGs - industrial developers, researchers, teachers, corporate decision makers, etc.-may find in this book a rich material for their work and inspiration for their activities. 


\section{References}

1. Connolly, T.M., Boyle, E.A., MacArthur, E., Hainey, T., Boyle, J.M.: A systematic literature review of the empirical evidence on computer games and serious games. Comput. Educ. 59(2), 661-686 (2012)

2. Wouters, P., van Oostendorp, H., van Nimwegen, C., van der Spek, E.D.: A meta-analysis of the cognitive and motivational effects of serious games. Comput. Educ. 60(1), 412-425 (2013)

3. Greitzer, F.L., Kuchar, O.A., Huston, K.: Cognitive science implications for enhancing training effectiveness in a serious gaming context. ACM J. Educ. Res. Comput. 7(3), 2:1-2:16 (2007)

4. Marfisi-Schottman, I., Labat, J.-M., Carron, T.: Building on the case teaching method to generate learning games relevant to numerous educational fields. In: IEEE International Conference on Advanced Learning Technologies (iCALT 2013), Beijing, China, 15-18 July 2013

5. Bellotti, F., Berta, R., De Gloria, A., D’Ursi, A., Fiore, V.: A serious game model for cultural heritage. ACM J. Comput. Cult. Herit. 5(4) (2012)

6. Howell, K., Glinert, E., Holding, L., Swain, C.: How to build serious games. Commun. ACM 50(7), 44-49 (2007)

7. Doucet, L., Srinivasan, V.: Designing entertaining educational games using procedural rhetoric: a case study. In: Proceedings of 5th ACM SIGGRAPH Symposium on Video Games, Los Angeles, CA, July 2010 (2010)

8. Berta, R., Bellotti, F., De Gloria, A., Pranantha, D., Schatten, C.: Electroencephalogram and physiological signal analysis for assessing flow in games. IEEE Trans. Comput. Intell. AI Games 5(2), 164-175 (2013)

9. Ninaus, M., Kober, S.E., Friedrich, E.V.C., Dunwell, I., de Freitas, S., Arnab, S., Ott, M., Kravcik, M., Lim, T., Louchart, S., Bellotti, F., Hannemann, A., Thin, A.G.G., Berta, R., Wood, G., Neuper, C.: Neurophysiological methods for monitoring brain activity in serious games and virtual environments: a review. Int. J. Technol. Enhanced Learn. (IJTEL) 6(1), 78-103 (2014)

10. Bellotti, F., Kapralos, B., Lee, K., Moreno-Ger, P., Berta, R.: Assessment in and of serious games: an overview. Adv. Hum. Comput. Interact. (2013). Article ID 136864. doi:10.1155/ 2013/136864

11. Shute, V.J, Ke, F.: Games, learning, and assessment. In: Ifenthaler, D., Eseryel, D., Ge, X. (eds.) Assessment in Game-Based Learning: Foundations, Innovations and Perspectives, pp. 43-58. Springer, New York (2012)

12. el Blanco, Á., Serrano-Laguna, Á., Freire, M., Martínez-Ortiz, I., Fernández-Manjón, B.: E-learning standards and learning analytics. Can data collection be improved by using standard data models? In: Proceedings of the IEEE Engineering Education Conference (EDUCON), pp. 1255-1261 (2013). doi:10.1109/EduCon.2013.6530268

13. Bellotti, F., Berta, R., De Gloria, A.: Designing effective serious games: opportunities and challenges for research. Special Issue: Creative learning with serious games. Int. J. Emerg. Technol. Learn. (IJET) 5, 22-35 (2010) 
14. Arnab, S., Lim, T., Carvalho, M.B., Bellotti, F., de Freitas, S., Louchart, S., Suttie, N., Berta, R., De Gloria, A.: Mapping learning and game mechanics for serious games analysis. Br. J. Educ. Technol. (2014). doi:10.1111/bjet.12113

15. Ritterfeld, U., Cody, M., Vorderer, P. (eds.) Serious Games: Mechanisms and Effects. Routledge, New York (2009) 


\section{Organization}

\section{General Chair}

Alessandro De Gloria University of Genoa, Italy

\section{General Co-chair}

Jean Menu Serious Game Lab, France

\section{Workshop and Tutorial Chair}

David Wortley

\section{Program Committee}

Aida Azadegan

Albert Angehrn

Alessandro Berni

Ana Paiva

Andreas Oikonomou

Anthony Brooks

Audrius Jurgelionis

Baltasar Fernández-Manjón

Bianca Falcidieno

Brian Goldiez

Carmen Padron

Carolina Islas Sedano

Christos Gatzidis

Damien Djaouti

Daniel Burgos

David Wortley

Dirk Ifenthaler

Donald Brinkman

Erik Duval

Erik van der Spek

Fabrizia Mantovani

Francesco Bellotti

Francisco José Gallego Durán
Gamification and Enabling Technologies, UK

University of the West Scotland, UK

INSEAD, France

NATO, Italy

INESC-ID, Portugal

University of Derby, UK

Aalborg University, Denmark

Fraunhofer, Germany

Complutense University of Madrid, Spain

CNR IMATI, Italy

University of Central Florida, USA

ATOS, Spain

University of Eastern Finland, Finland

Bournemouth University, UK

IRIT, France

UNIR, Spain

Gamification and Enabling Technologies, UK

Open Universities Australia, Australia

Microsoft, USA

Katholieke Universiteit Leuven, Belgium

Technical University of Eindhoven,

The Netherlands

Università di Milano Bicocca, Italy

University of Genoa, Italy

University of Alicante, Spain 
Frank Dignum

George Lepouras

Igor Mayer

Ioana Stanescu

Ion Roceanu

Ivan Lombardi

J.C. Hertz

Jannicke M. Baalsrud Hauge

Johann Riedel

Josef Froschauer

Kam Star

Katerina Mania

Kristian Kiili

Kurt Debattista

Kyung-Sik Kim

Leonardo Caporarello

Lucia Pannese

Marcello Carrozzino

Margarida Romero

Maria Magdalena Popescu

Marius Preda

Mark McMahon

Matthias Rauterberg

Michael Derntl

Michael Kickmeier-Rust

Michela Mortara

Miguel Encarnação

Milos Kravcik

Muriel Ney

Nahum D. Gershon

Nathalie Charlier

Norman Badler

Ole-Ivar Holthe

Olivier Irrmann

Pablo Moreno-Ger

Panagiotis Petridis

Paolo Riva

Per Backlund

Peter Van Rosmalen

Rafael Bidarra

Ralph Klamma

Riccardo Berta
University of Utrecht, The Netherlands

University of Peloponnese, Greece

Technical University of Delft, The Netherlands

Carol I National Defence University, Romania

Carol I National Defence University, Romania

Catholic University Sacred Heart, Italy

Author of Joystick Nation, USA

Bremer Institut für Produktion und

Logistik GmbH, Germany

University of Nottingham, UK

Vienna University of Technology, Austria

Playgen, UK

Technical University of Crete, Greece

Tampere University of Technology, Finland

University of Warwick, UK

Dankook University, South Korea

SDA Bocconi School of Management, Italy

imaginary, Italy

Institute for Advanced Studies Lucca, Italy

Esade, Spain

Carol I National Defence University, Romania

Institut National des Télécommunications, France

Edith Cowan University, Western Australia

Technical University of Eindhoven,

The Netherlands

RWTH Aachen University, Germany

Technical University of Graz, Austria

CNR, Italy

University of Louisville, USA

RWTH Aachen University, Germany

Imag, France

MITRE, USA

Katholieke Universiteit Leuven, Belgium

University of Pennsylvania, USA

Geelix, Norway

Aalto University, Finland

Complutense University of Madrid, Spain

Serious Games Institute, UK

Università di Milano Bicocca, Italy

Högskolan i Skövde, Sweden

Open University of the Netherlands,

The Netherlands

Delft University of Technology,

The Netherlands

RWTH Aachen University, Germany

University of Genoa, Italy 
Rob Nadolsky

Rosa Maria Bottino

Rui Prada

Sandy Louchart

Sara de Freitas

Simon Egenfeldt-Nielsen

Staffan Bjork

Stephen Lane

Steve Ellis

Sung Hyun Cho

Tanya Krzywinska

Theo Lim

Travis Ross

William Fisher

Wim Westera

Yiorgos Chrysanthou
Open University of the Netherlands, The Netherlands

National Research Institute, Italy

INESC-ID, Portugal

Heriot-Watt University, UK

Coventry University, UK

Serious Games Interactive, Denmark

Chalmers, Sweden

University of Pennsylvania, USA

NASA, USA

Hongik University, South Korea

Brunel University, UK

Heriot-Watt University, UK

Indiana University, USA

Quicksilver, USA

Open University of the Netherlands, The Netherlands

University of Cyprus, Cyprus

\section{Local Arrangements Committee}

Patricia Doherty

Caroline Freyther

Claudia Schoke

Elisa Lavagnino

\section{Publications Chair}

Riccardo Berta

\section{Communication Chair}

Francesco Bellotti

\section{Administrative Chair}

Patricia Doherty

Elisa Lavagnino
Dassault Systèmes, France

Dassault Systèmes, France

Dassault Systèmes, France

University of Genoa, Italy

University of Genoa, Italy

University of Genoa, Italy

Dassault Systèmes, France

University of Genoa, Italy 


\section{Contents}

\section{SG Design}

Energy-Efficient and Safe Driving Using a Situation-Aware Gamification Approach in Logistics . . . . . . . . . . . . . . . . . . . . . . . . . . .

Roland Klemke, Milos Kravcik, and Felix Bohuschke

Learning Analytics and Educational Games: Lessons Learned from Practical Experience. . . . . . . . . . . . . . . . . . . . . . . .

Ángel Serrano-Lagunaa, Javier Torrentea, Borja Maneroa, Ángel del Blancoa, Blanca Borro-Escribanoa, Iván Martínez-Ortiza, Manuel Freirea, and Baltasar Fernández-Manjón

Designing Games with a Purpose for Data Collection in Music Research. Emotify and Hooked: Two Case Studies . . . . . . . . . . . . . . . . . . . . . .

Anna Aljanaki, Dimitrios Bountouridis, John Ashley Burgoyne, Jan Van Balen, Frans Wiering, Henkjan Honing, and Remco Veltkamp

Learning Analytics in Serious Gaming: Uncovering the Hidden Treasury of Game Log Files . . . . . . . . . . . . . . . . . . . . . . . . . . . . . . . .

Wim Westera, Rob Nadolski, and Hans Hummel

Generating Computational Models for Serious Gaming . . . . . . . . . . . Wim Westera

COmBI naTion: The Fusion of Serious Gaming and COBIT . . . . . . . . .

Martin Fritsch, Sascha Müeller-Feuerstein, and Rainer Groß

The Move Beyond Edutainment: Have We Learnt Our Lessons from Entertainment Games? . . . . . . . . . . . . . . . . . . . . . . .

Aida Azadegan, Jannicke Balsrud Hauge, Francesco Bellotti, Riccardo Berta, Rafael Bidarra, Casper Harteveld, Johann C.K.H. Riedel, and Ioana Andreea Stanescu

Flooded: A Location-Based Game for Promoting Citizens' Preparedness

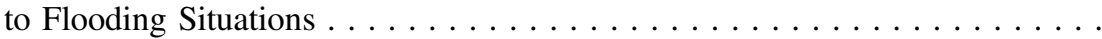

Sondre Johan Mannsverk, Ines Di Loreto, and Monica Divitini

\section{SG Technology}

Development of a Game Engine for Accessible Web-Based Games . . . . . . . .

Javier Torrente, Ángel Serrano-Laguna, Ángel del Blanco Aguado, Pablo Moreno-Ger, and Baltasar Fernández-Manjón 
FILTWAM and Voice Emotion Recognition. ................

Kiavash Bahreini, Rob Nadolski, and Wim Westera

A Survey of Haptics in Serious Gaming. . . . . . . . . . . . .

Shujie Deng, Jian Chang, and Jian J. Zhang

An Agent Based Methodology to Design Serious Game in Social Field.... . Manuel Gentile, Dario La Guardia, Valentina Dal Grande, Simona Ottaviano, and Mario Allegra

Lecture Notes in Computer Science: Beyond simulators, Using F1 Games to Predict Driver Performance, Learning and Potential. . . . . . . . . . . Matthew Hislop, Aparajithan Sivanathan, Theodore Lim, James M. Ritchie, Gnanathusharan Rajendran, and Sandy Louchart

Paths for Cognitive Rehabilitation: From Reality to Educational Software, to Serious Games, to Reality Again. . . . . . . . . . . . . . . . . Francesco Curatelli, Chiara Martinengo, Francesco Bellotti, and Riccardo Berta

Towards an Understanding of the Relationship Between Executive Functions and Learning Outcomes from Serious Computer Games ........ James Boyle and Elizabeth A. Boyle

Flow Experience as a Quality Measure in Evaluating Physically Activating Serious Games . . . . . . . . . . . . . . . . . . . . . . . Kristian Kiili, Arttu Perttula, Sylvester Arnab, and Marko Suominen

\section{SG Applications}

A Business Simulation with an Agent-Based Deliberative Model of Consumer Behaviour.

Márcia L. Baptista, Carlos Martinho, Francisco Lima, Pedro A. Santos, and Helmut Prendinger

Stealth Assessment of Teams in a Digital Game Environment. . . . . . . . . 224 Igor Mayer, Dirk van Dierendonck, Theo van Ruijven, and Ivo Wenzler

Unveiling California History Through Serious Games: Fort Ross Virtual Warehouse .............................. Nicola Lercari, Michela Mortara, and Maurizio Forte

Entrepreneurship Competence Assessment Through a Game Based Learning MOOC . . . . . . . . . . . . . . . . . . . . . Mireia Usart and Margarida Romero 
Evaluation of "Cultural Awareness - Afghanistan Pre-deployment":

A User Study . . . . . . . . . . . . . . . . . . . . . . . . . .

Alessandra Tesei, Alessandra Barbieri, Ion Roceanu, and Daniel Beligan

Evaluating the Effectiveness of Serious Games for Cultural Awareness:

The Icura User Study . . . . . . . . . . . . . . . . . . . . . . . . . .

Michela Mortara, Chiara Eva Catalano, Giusy Fiucci, and Michael Derntl

Beyond Gambling Temptations: An Experimental Design Project to Detoxify

Players from Irresistible Illusions of Gambling . . . . . . . . . . . . . . . Annamaria Andrea Vitali, Margherita Pillan, and Pietro Righi Riva

Player-Specific Conflict Handling Ontology . . . . . . . . . . . . . . . . .

Charline Hondrou, Eleni Tsalapati, Amaryllis Raouzaiou, Kostas Karpouzis, and Stefanos Kollias

Doing Useful Work Using Games . . . . . . . . . . . . . . . . Kam Star

\section{Workshop}

Acquiring 21st Century Skills: Gaining Insight into the Design and

Applicability of a Serious Game with 4C-ID . . . . . . . . . . . . .

Peter van Rosmalen, Elizabeth A. Boyle, Rob Nadolski,

John van der Baaren, Baltasar Fernández-Manjón, Ewan MacArthur,

Tiina Pennanen, Madalina Manea, and Kam Star

\section{Posters}

An Instructional Approach for Developing Serious Games . . . . . . . . . . . .

Félix Buendía-García, Sol García-Martínez, Eva Ma Navarrete-Ibañez, and $M^{a}$ Jesús Cervelló-Donderis

User Profiling: Towards a Facebook Game that Reveals Cognitive Style . . . . Angeliki Antoniou, Ioanna Lykourentzou, Jenny Rompa, Eric Tobias, George Lepouras, Costas Vassilakis, and Yannick Naudet

Quantitative Approach in Measuring Knowledge Convergence

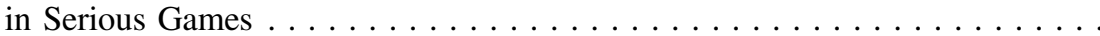

Ariadna Padrós and Margarida Romero

The 5/10 Method: A Method for Designing Educational Games . . . . . . . . . .

Johan Jeuring, Rick van Rooij, and Nicolas Pronost

Balancing Fidelity of Simulation Game Environments to Increase

Situational Awareness Skills. . . . . . . . . . . . . . . . . . Heide Lukosch 
Gaming for Policy Makers: It's Serious! . . . . . . . . . . . . . 376 Josine G.M. van de Ven, Hester Stubbé, and Micah Hrehovcsik

Serious Game Design for Vehicular Language Learning Addressing Work Needs................................. 383

Hariklia Tsalapatas, Olivier Heidmann, Rene Alimisi, Spyros Tsalapatas, Spyros Kourias, Martin Sillaots, Bernando Hourmat, Michela Tramonti, Steffan Oie, and Elias Houstis

Harmonizing Interoperability - Emergent Serious Gaming in Playful Stochastic CAD Environments . . . . . . . . . . . . . . . . . . . Z. Kosmadoudi, Theodore Lim, James M. Ritchie, Y. Liu, R. Sung, Jannicke Balsrud Hauge, Samir Garbaya, Robert E. Wendrich, and Ioana A. Stanescu

A Diagnostic Tool on Time Perception of Children with ADHD 400 Pongpanote Gongsook, Janneke Peijnenborgh, Christian Sallustro, Erik van der Spek, Jun Hu, Francesco Bellotti, Matthias Rauterberg, and Jos Hendriksen 